\title{
Notes on the vocalizations of Common Fiscal (Lanius collaris)
}

Peter Boesman

In the following we briefly analyze and compare voice of the different races of Common Fiscal (Lanius collaris). We also try to quantify the extent of any vocal differences using the criteria proposed by Tobias et al. (2010), as a support for taxonomic review.

We have made use of sound recordings available on-line from Xeno Canto (XC) and Macaulay Library (ML).

Our main aim is to compare voice of the 'Southern Fiscal' group vs the 'Northern Fiscal' group, as in some taxonomies these are considered distinct species.

'Southern Fiscal' group (only recordings from South Africa: race collaris)

Song is a repeated phrase of some melodious whistles:

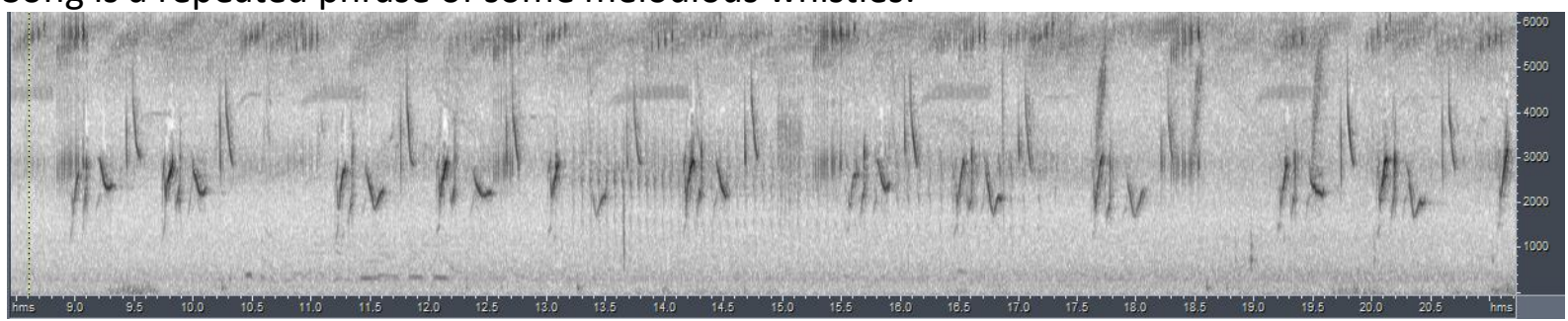

usually with harsh scratchy notes mixed in:

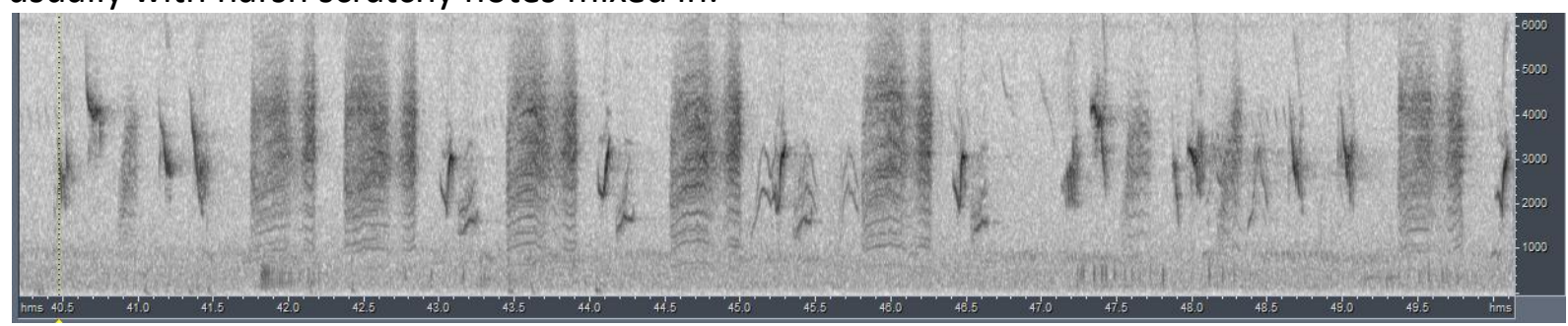

or predominantly these harsh scratchy notes:

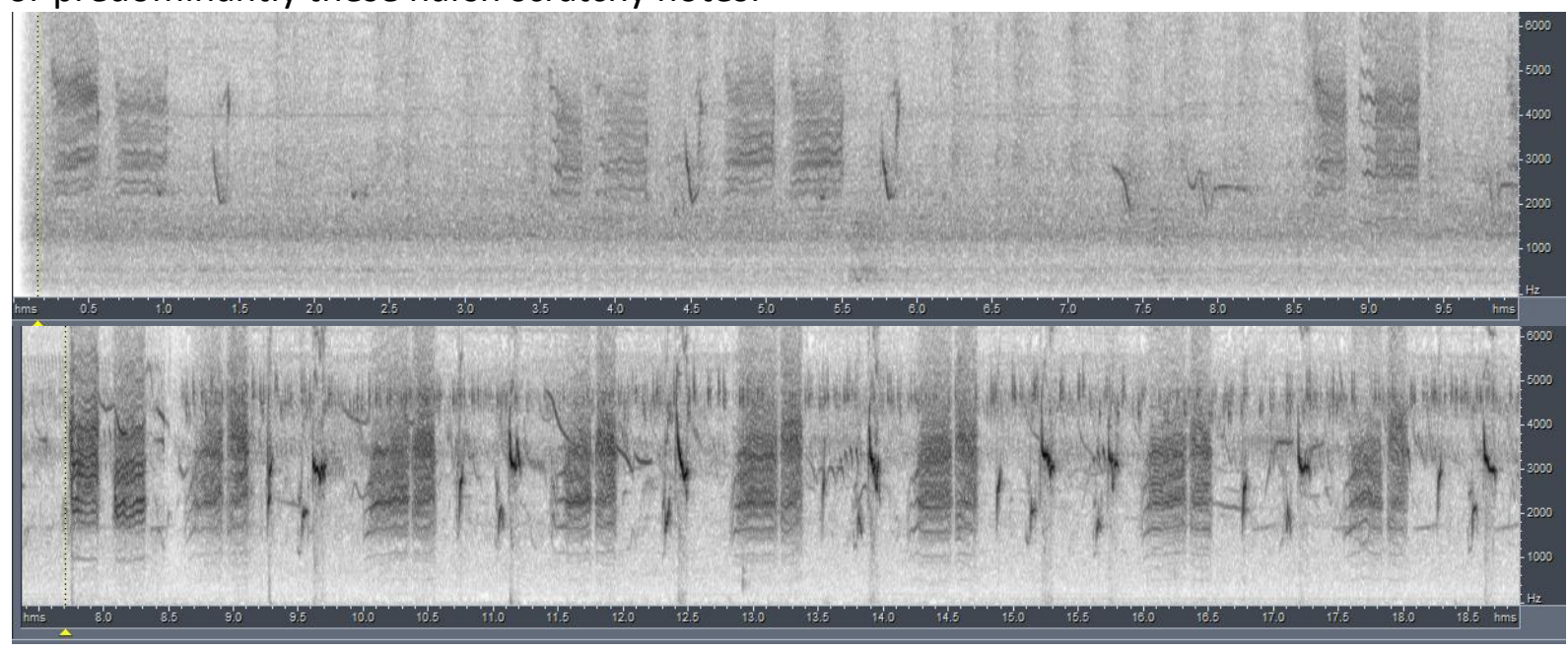




\section{HANDBOOK OF THE \\ BIRDS PF,THE WORLD \\ Alve}

\section{ORNITHOLOGICAL NOTES}

Voice of 'Northern Fiscal group' is very different, but there are racial/regional differences:

Kenya (race humeralis):

A rather hoarse screechy call:

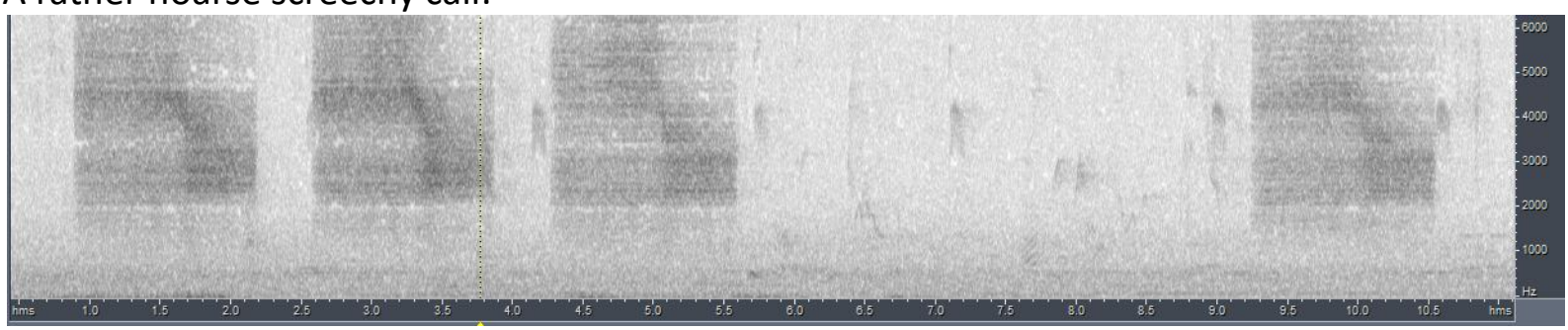

sometimes sounding more burry:

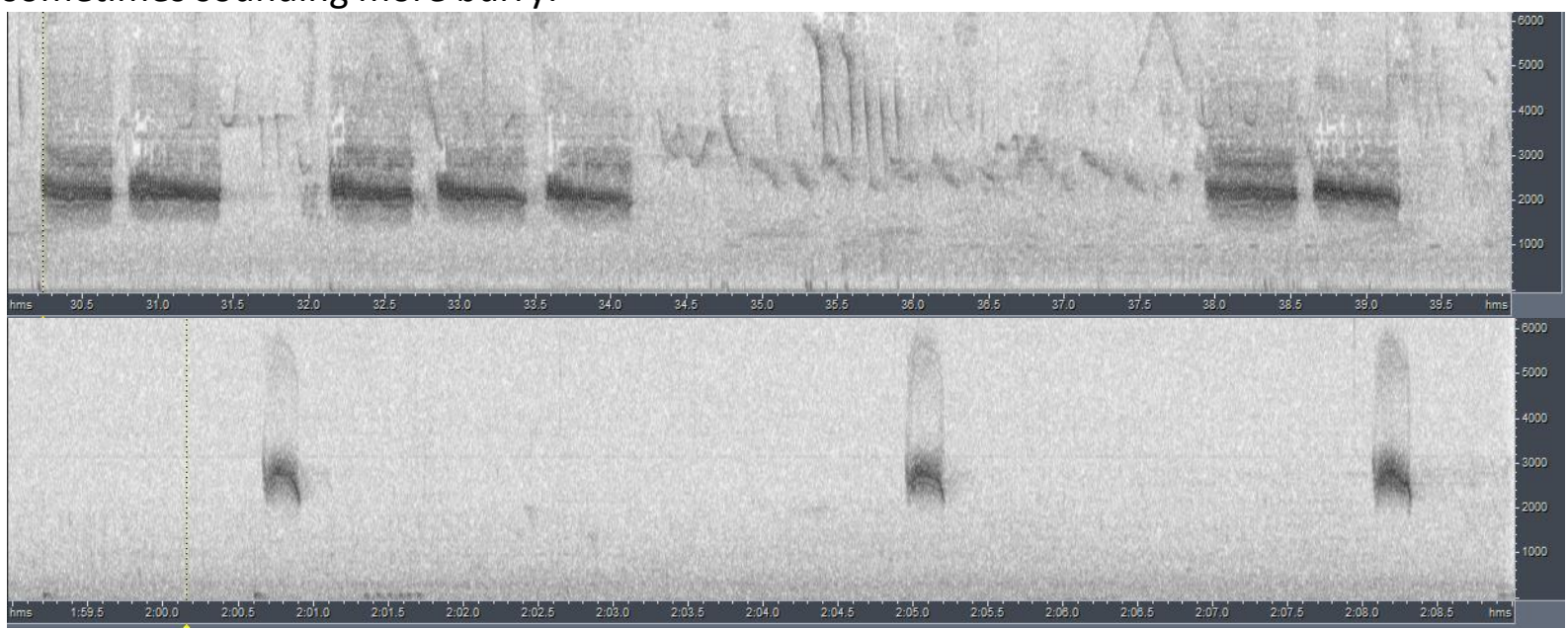

or quite melodious:

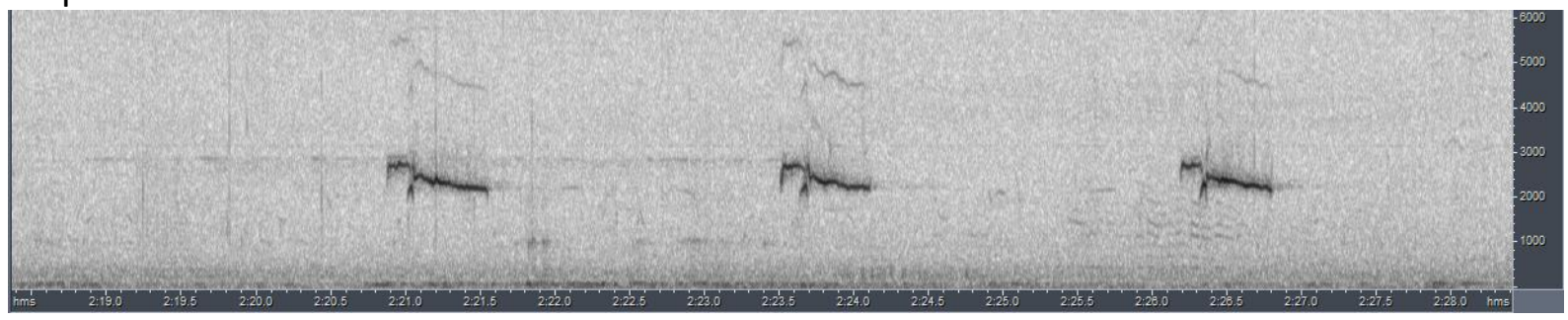

a short series of a repeated fluting whistle

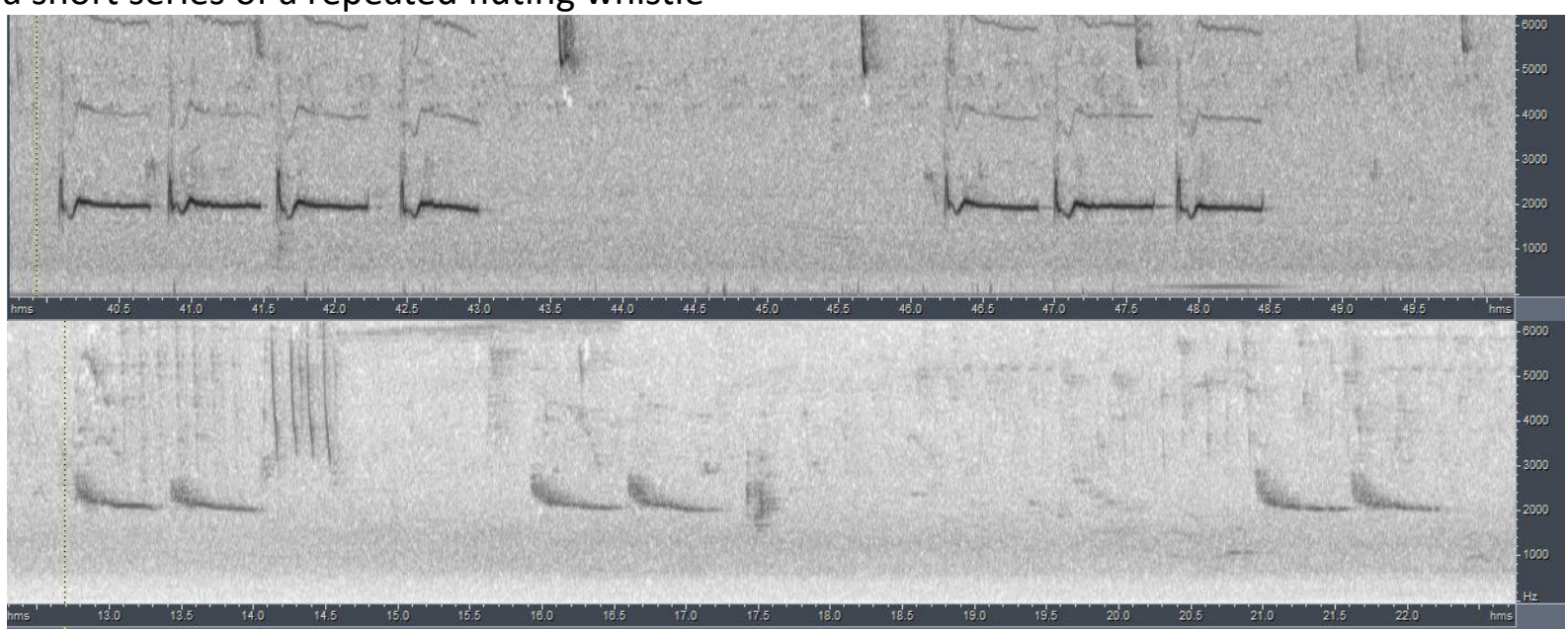




\section{HANDBOOK OF THE \\ BIRDSPITTE WORLD \\ Aluve}

\section{ORNITHOLOGICAL NOTES}

\section{Ethiopia (race humeralis)}

A short series of repeated hollow notes

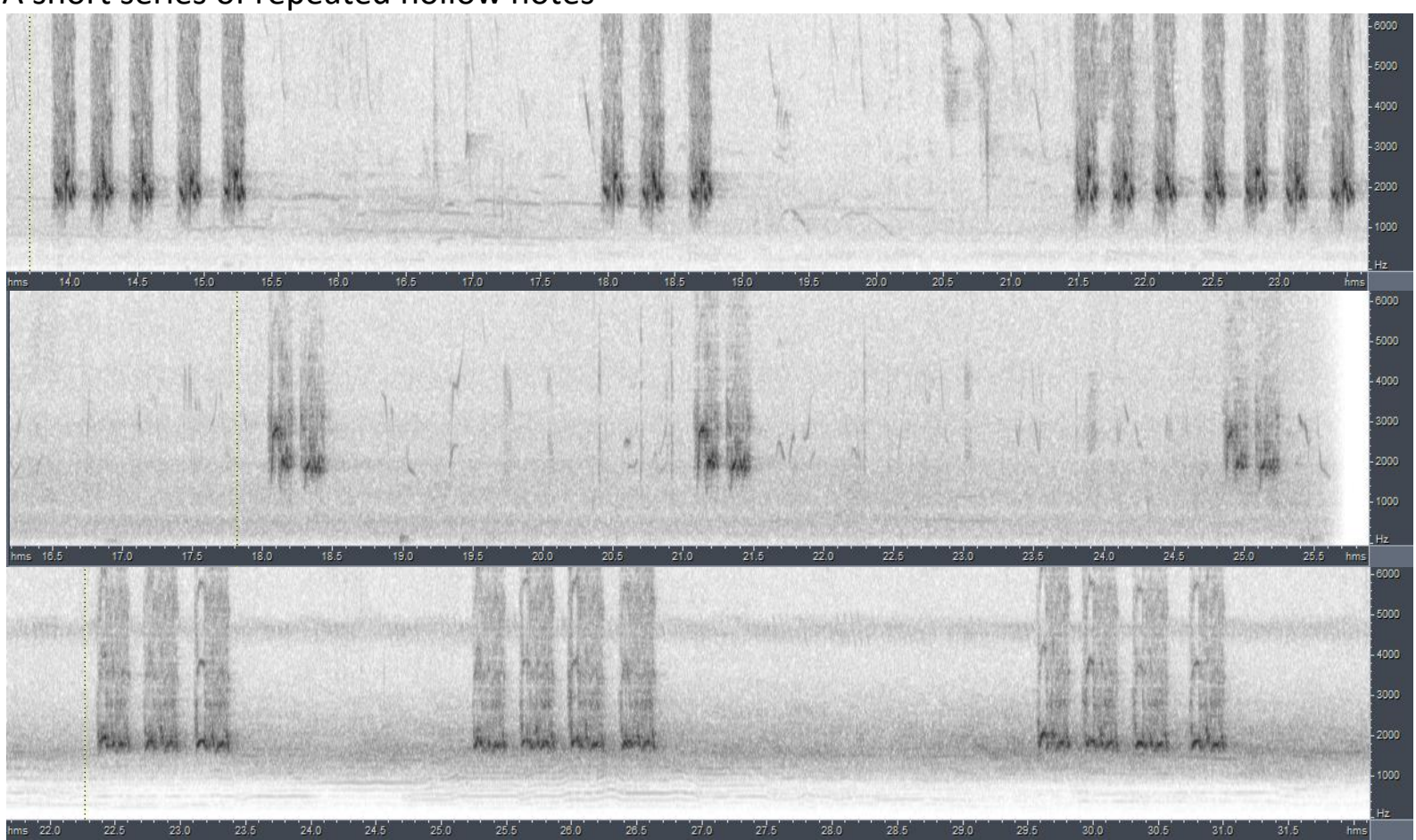

or more melodious whistles (similar to Kenya):
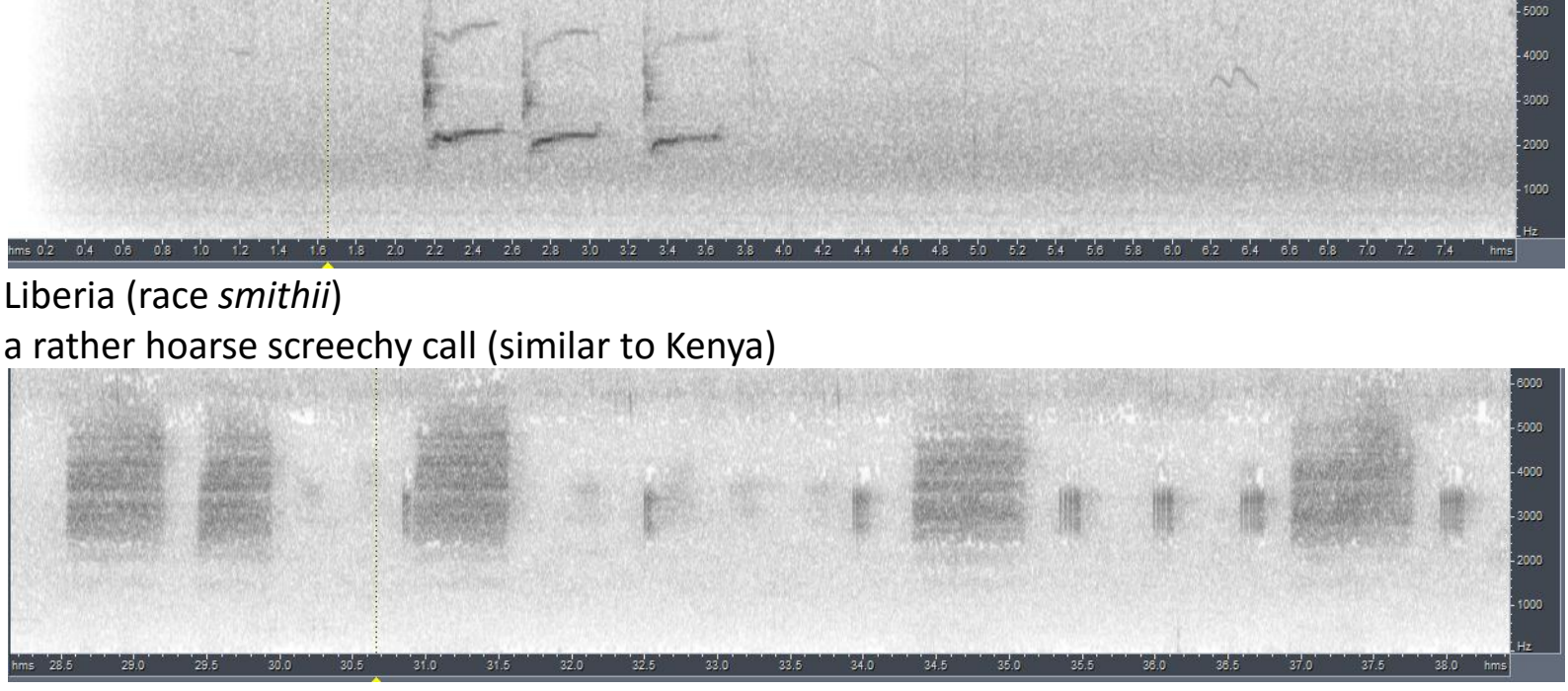

NE Congo (race smithii)

a rather hoarse screechy call (similar to Kenya)

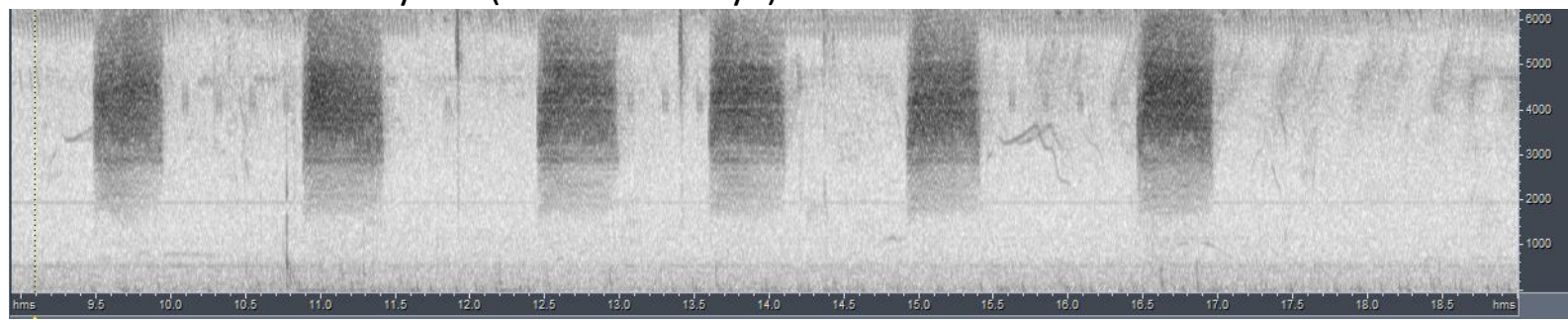



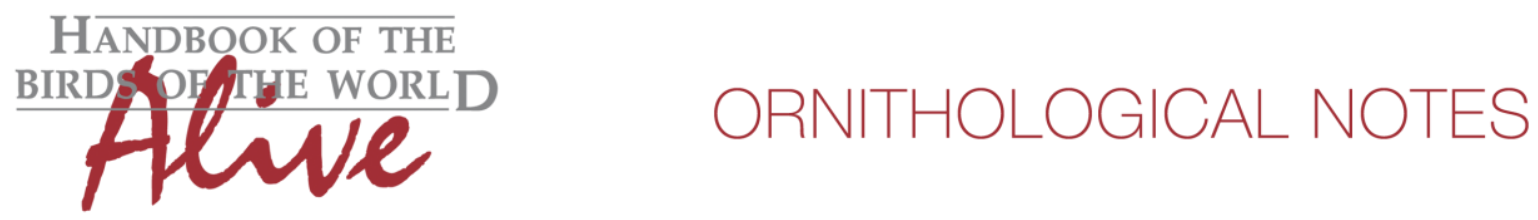

There is clearly still a lot to be discovered about the voice of all races, as we only have recordings of some vocalizations of three races (out of eight), with mainly a blind spot in SC Africa. Based on the available evidence the difference between the Northern and Southern group seems to be quite obvious:

'Northern Fiscal' utters mainly short series of repeated notes which are quite variable, either screechy, burry or hollow and occasionally quite melodious, pure and rather flat-pitched, with variable pauses in between.

'Southern Fiscal' utters a continuous series of fairly complex whistles usually alternated with harsh scratchy notes, the latter occasionally becoming the main component.

Vocal differences can be quantified based on song phrase duration and pauses (score 1-2), number of single note repeats (2) and distinct vocabulary with very different note shapes (e.g. long, rather flat-pitched notes of Northern vs. short, mainly up/down-slurred notes of Southern, score 1-2), leading to an estimated score of 3.

This note was finalized on 25th January 2016, using sound recordings available on-line at that moment. We would like to thank in particular the sound recordists who placed their recordings for this species on XC and ML: Peter Boesman, James Bradley, Jennifer Home, Peter Kaestner, Rory Nefdt, Stein Nilsen, Myles North, Bram Piot, Lynette Rudman and Andrew Spencer.

\section{References}

Tobias, J.A., Seddon, N., Spottiswoode, C.N., Pilgrim, J.D., Fishpool, L.D.C. \& Collar, N.J. (2010). Quantitative criteria for species delimitation. Ibis 152(4): 724-746.

\section{Recommended citation}

Boesman, P. (2016). Notes on the vocalizations of Common Fiscal (Lanius collaris). HBW Alive Ornithological Note 201. In: Handbook of the Birds of the World Alive. Lynx Edicions, Barcelona. (retrieved from http://www.hbw.com/node/932147 on 1 September 2016). 